\title{
Clinical and Biochemical Characteristics and Aetiology of Asymptomatic Raised Alanine Aminotransferase in Newly Detected Diabetes and Impaired Glucose Tolerance Patients
}

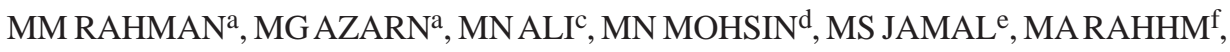 \\ HAHMED', MN HOQUU' ${ }^{\text {, TM BUIYAN }}{ }^{\mathrm{i}}$, MARAHMAN ${ }^{\mathrm{j}}$
}

Summary:

Objectives: Clinical evaluation and identification of aetiology of asymptomatic raised serum alanine aminotransferase (ALT) level in newly detected adult diabetic and impaired glucose tolerance (IGT) patients.

Methods: In this cross-sectional study, newly detected adult diabetic and IGT patients having asymptomatic raised serum ALT level of $>1.5$ times of upper limit of normal were evaluated clinically and by laboratory tests.

Results: Total number of patients was 120, which was 3.1\% of all newly registered diabetic and IGT patients over the study period. Male were 74 and female 46. Diabetes mellitus (DM) was found in $93.3 \%$ cases and IGT in $6.7 \%$. Mean age was 43.1 years, mean body weight was $64.5 \mathrm{~kg}$ and mean body mass index (BMI) was $25.5 \mathrm{~kg} / \mathrm{m}^{2}$. Central (abdominal) obesity was found in $61.5 \%$ cases. Increased waist hip ratio

Introduction:

The prevalence of diabetes mellitus (DM) is increasing day by day. Patients with DM often have elevated levels of alanine aminotransferase (ALT). ${ }^{1}$ Majority of them remain asymptomatic or have non-specific symptoms. The prevalence of asymptomatic elevated ALT is much higher was found in $86.3 \%$ cases. Hypertension and hepatomegaly were present in $35 \%$ and $5.8 \%$ cases respectively. Dyslipidaemia was found in $98.3 \%$ cases and $45 \%$ patients fulfilled criteria for metabolic syndrome. Regarding etiology, $76.7 \%$ cases had non-alcoholic fatty liver disease (NAFLD), 8.3\% had HBsAg sero-positivity, $4.2 \%$ had anti-HCV seropositivity and 3.3\% had both NAFLD and HBsAg seropositivity. In $7.5 \%$ cases no cause was found. Raised serum ALT level had a significant correlation with metabolic syndrome ( $p=0.016)$ and increasing age $(p=0.008)$.

Conclusion: Elevation of serum ALT is common in DM and IGT. NAFLD is the commonest cause followed by hepatitis $B$ and $C$ virus infection.

Keywords: alanine aminotransferase, asymptomatic, diabetes mellitus, impaired glucose tolerance, non-alcoholic fatty liver disease.

(J Banagladesh Coll Phys Surg 2015; 33: 70-74)

in diabetic population than non-diabetic counterpart. ${ }^{1}$ Elevated ALT is often a marker for non-alcoholic fatty liver disease (NAFLD), chronic hepatitis $B$ and $C$ virus infection and metabolic syndrome. ${ }^{2}$ Up to $70 \%$ of type 2 diabetic patients may have NAFLD. ${ }^{3}$ A strong association remains between hepatitis $\mathrm{C}$ virus (HCV) infection and type $2 \mathrm{DM}^{4-}$

a. Dr. Md. Mahbubur Rahman, Senior Medical Officer, Dept. of Gastroenterology, BIRDEM General Hospital, Dhaka, Bangladesh

b. Dr. Md. Golam Azam, Junior Consultant, Dept. of Gastroenterology, BIRDEM General Hospital, Dhaka, Bangladesh

c. Dr. Md. Nowshad Ali, Department of Gastroenterology, SSMC\& Mitford Hospital, Dhaka, Bangladesh

d. Dr. Mostafa Nur Mohsin, Resident Physician, Sadar Hospital, Cox’s Bazar, Bangladesh

e. Dr. Md. Shah Jamal, Junior Consultant (Medicine), 200 Bedded General Hospital, Narayangonj, Bangladesh

f. Dr. Muhammad Abdur Rahim, Registrar, Dept. of Medicine, BIRDEM General Hospital, Dhaka, Bangladesh

g. Dr. Habib Ahmed, Deputed at BIRDEM General Hospital, OSD, DGHS of Bangladesh

h. Dr. Md. Nazmul Hoque, Junior Consultant, Dept. of Gastroenterology, BIRDEM General Hospital, Dhaka, Bangladesh

i. Dr. Tareq Mahmud Buiyan, Associate Professor, Dept. of Gastroenterology, BIRDEM General Hospital, Dhaka, Bangladesh

j. $\quad$ Dr. Md. Anisur Rahman, Professor, Dept. of Gastroenterology, BIRDEM General Hospital, Dhaka, Bangladesh

Address of Correspondence: Dr. Md. Mahbubur Rahman, Senior Medical Officer, Department of Gastroenterology, BIRDEM General Hospital, Dhaka, Bangladesh, Cell: 01741009000.

Received: 9 February, 2014

Accepted: 8 June, 2014 
${ }^{6} \mathrm{HCV}$ related morbidity and mortality is higher in patients with DM than patients without DM. ${ }^{7}$ Chronic hepatitis B virus (HBV) infection is also significantly higher in diabetic population. 8 ,9 If inadequately addressed, the spectrum of NAFLD can pass through simple hepatic steatosis to nonalcoholic steatohepatitis (NASH) to cirrhosis to hepatocellular carcinoma and death. ${ }^{10-16}$ In this study, we have tried to clinically evaluate adult newly detected impaired glucose tolerance (IGT) and diabetic patients with asymptomatic elevated ALT and to find out the aetiology for raised ALT.

\section{Materials and Methods:}

In this prospective cross-sectional study adult newly detected IGT and DM patients with elevated $(>1.5$ times of upper normal limit) ALT were evaluated at Bangladesh Institute of Research and Rehabilitation in Diabetes, Endocrine and Metabolic Disorders (BIRDEM), Dhaka, Bangladesh from August to October 2009. Patients with diagnosis of chronic liver disease, acute hepatitis, congestive cardiac failure and history of regular alcohol or hepatotoxic drug intake were excluded from the study. The study was approved by the ethical review committee of Diabetic Association of Bangladesh. Informed written consent was taken from every patient after explaining the purpose and procedure. A standard questionnaire was filled up. Every patient was clinically evaluated and supplemented by appropriate laboratory investigations.

\section{Anthropometric measurement}

This included weight and height. Body mass index (BMI) was calculated as body weight in kilogram divided by height in meters square. Waist circumference was measured at the horizontal plane mid-way between anterior superior iliac spine and lower costal margin at the narrowest part of the waist line while the patient was standing and at the end of normal expiration. Hip circumference was measured at a horizontal plane passed through greater trochanter of femur on both side in standing position.

\section{Blood Pressure}

Blood pressure (BP) was measured by using a standard sphygmomanometer in the supine position after rest for at least 15 minutes. Hypertension was considered with blood pressure $>130 / 85 \mathrm{mmHg}$ and / or patient on regular use of anti-hypertensive medication.

\section{Biochemical tests}

All patients underwent the following tests: oral glucose tolerance test (OGTT), fasting lipid profile, serum ALT level, HBsAg, anti-HCV, ultrasonography of hepatobiliary system and pancreas. Additional investigations were done as required. Plasma glucose was measured by glucose oxidase method. Fasting plasma triglycerides (TG), high density lipoprotein cholesterol (HDL-c), low density lipoprotein cholesterol (LDL-c) were measured by enzymetic colorimetric method and total cholesterol was measured by enzymatic endpoint method using reagents of Randox Laboratories Ltd., UK. HBsAg was measured by micro-particle enzyme immune-assay (MEIA) method and anti-HCV was measured by ELISA.

\section{Dyslipidemia}

Dyslipidaemia was defined according to National Cholesterol Education Programme (NCEP) Adult Treatment Panel (ATP) III criteria- plasma triglyceride (TG) $>150 \mathrm{mg} / \mathrm{dl}$, plasma total cholesterol > 200mg/dl, plasma HDL-c $<40 \mathrm{mg} / \mathrm{dl}$ in male $/<50 \mathrm{mg} / \mathrm{dl}$ in female or plasma LDL-c $>100 \mathrm{mg} / \mathrm{dl}$.

\section{Metabolic syndrome}

Metabolic syndrome was defined according to International Diabetic Federation (IDF) criteria- central obesity (waist circumference $>90 \mathrm{~cm}$ for male and $>80 \mathrm{~cm}$ for female as for Asian) plus any two of the followings four criteria: (1) Raised plasma TG level $>150 \mathrm{mg} / \mathrm{dl}$ or $>1.7 \mathrm{mmol} / \mathrm{L}$ or specific treatment for this lipid abnormality. (2) Low plasma HDL-c $<40 \mathrm{mg} / \mathrm{dl}$ or $<1.03 \mathrm{mmol} / \mathrm{L}$ for males or $<50 \mathrm{mg} / \mathrm{dl}$ or $<1.29 \mathrm{mmol} / \mathrm{L}$ for females or specific treatment for this lipid abnormality, (3) Raised BP: systolic blood pressure $>130 \mathrm{~mm}$ Hg or diastolic blood pressure $>85 \mathrm{mmHg}$, (5) Fasting plasma glucose $\geq 6.1 \mathrm{mmol} / \mathrm{L}$.

\section{Abdominal ultrasound examination}

This was performed in all enrolled patients fasting for at least 10 hours by a single sonographer using SIEMENS Sonoline Antares. Liver echo pattern was graded as follow:

Grade I (mild): A single diffuse increase in fine echoes in the hepatic parenchyma with normal visualization of the diaphragm and intrahepatic vessel borders.

Grade II (moderate): A moderate diffuse increase in fine echoes with slightly impaired visualization of the intrahepatic vessels and diaphragm.

Grade III (marked): A marked increase in fine echoes with poor or no visualization of the intra-hepatic vessel borders, diaphragm and posterior portion of the right lobe of the liver.

\section{Statistical Analysis}

Analysis was performed using statistical package for social science (SPSS) version 12. Data were expressed as mean, standard deviation (SD), percentage etc. Chi- 
square test $\left(\mathrm{x}^{2}\right)$ was used for the comparison of qualitative data. Results were considered statistically significant at $\mathrm{p}<0.05$. Statistical analysis for association between raised serum ALT level and clinical parameter, biochemical parameter as well as ultrasonographic findings of hepatobilliary system were performed using univariate analysis with SPSS windows programme.

\section{Results:}

Over the study period a total of 3871 adult newly detected IGT and DM patients were enrolled in BIRDEM. Among them 120 patients were found to have asymptomatic elevated ALT of $>1.5$ times of upper normal limit (UNL) (considering exclusion criteria) which was 3.1\%. Sixty (50\%) of study subjects had ALT between 2-5 times of UNL, 52 (43\%) had $<2$ times of UNL and 8 (7\%) had $>5$ times of UNL. Central obesity, increased waist hip ratio, hypertension, hepatomegaly, dyslipidaemia, fatty liver and metabolic syndrome were present in $61.5 \%, 86.3 \%, 35 \%$, $5.8 \%, 98.3 \%, 76.7 \%$ and $45 \%$ cases respectively. Base-line demographic, clinical and biochemical characteristics of the study subjects are shown in table I and II.

Raised serum ALT level had a significant correlation with the age of the study subjects (P 0.008) and metabolic syndrome (P0.016), but not with BMI (P0.891) (Table III).

NAFLD was the commonest aetiology for raised ALT in this study (Table IV). Other causes included hepatitis B and $C$ virus infection. In $7.5 \%$ cases no cause could be identified.

\section{Table-I}

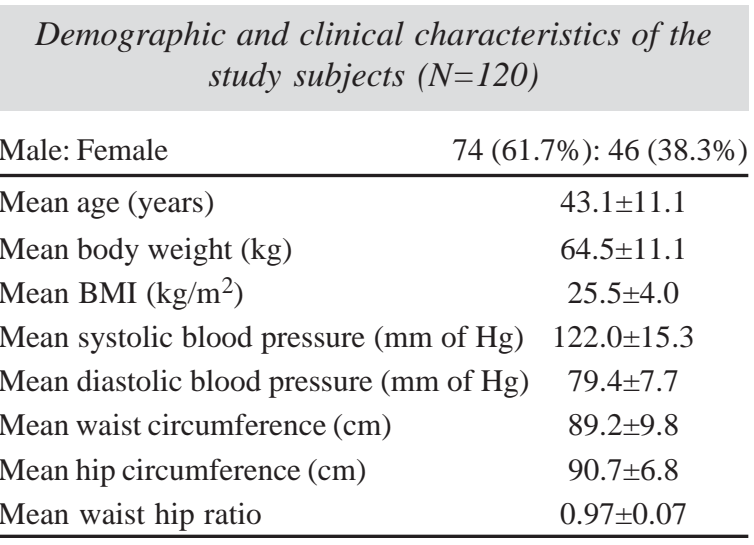

Table II

Biochemical characteristics of the study subjects $(N=120)$

\begin{tabular}{lc}
\hline Mean fasting plasma glucose (m.mol/L) & $11.9 \pm 4.9$ \\
Mean 2 hour after 75 gm glucose (m.mol/L) & $19.2 \pm 7.2$ \\
Mean ALT (U/L) & $103.1 \pm 54.1$ \\
Mean total cholesterol (mg/dl) & $196.3 \pm 44.9$ \\
Mean triglycerides (mg/dl) & $187.9 \pm 99.9$ \\
Mean HDL-c (mg/dl) & $36.8 \pm 8.2$ \\
Mean LDL-c (mg/dl) & $125.8 \pm 36.6$ \\
\hline
\end{tabular}

Table-III

Frequency of raised ALT for different risk factors among the study subjects $(N=120)$

\begin{tabular}{lcccc}
\hline Risk factors & ALT $<2$ XUNL (52, 43\%) & ALT $>2$ XUNL(68, 57\%) & Total(120) & P value \\
\hline Age (years) & & & & \\
$<35$ & $7(5.8 \%)$ & $26(21.7 \%)$ & $33(27.5 \%)$ & \\
$35-50$ & $29(24.7 \%)$ & $30(25 \%)$ & $59(49.2 \%)$ & 0.008 \\
$>50$ & $16(13.3 \%)$ & $12(10 \%)$ & $28(23.3 \%)$ & \\
Sex & & & & \\
Male & $34(28.3 \%)$ & $40(33.3 \%)$ & $74(61.7 \%)$ & 0.464 \\
Female & $18(15 \%)$ & $28(23.3 \%)$ & $46(38.3 \%)$ & \\
BMI (kg/m²) & $23(19.2 \%)$ & $31(25.8 \%)$ & $54(45 \%)$ & \\
$18.5-24.9$ & $23(19.2 \%)$ & $28(23.3 \%)$ & $51(42.5 \%)$ & 0.891 \\
$25-29.9$ & $6(5 \%)$ & $9(7.5 \%)$ & $15(12.5 \%)$ & \\
e”30 & & & & \\
Metabolic syndrome & $30(25 \%)$ & $24(20 \%)$ & $54(45 \%)$ & 0.016 \\
Present & $22(18.3 \%)$ & $44(26.7 \%)$ & $66(55 \%)$ & \\
Absent & & & & \\
Fatty liver (on USG) & $42(35 \%)$ & $50(41.7 \%)$ & $92(76.7 \%)$ & 0.681 \\
Present & $10(8.3 \%)$ & $18(15 \%)$ & $28(23.3 \%)$ & \\
Absent & & &
\end{tabular}


Table-IV

Aetiology of raised ALT in newly detected DM and IGT patients

\begin{tabular}{lccc} 
Aetiology & Total $(\mathrm{N}=120)$ & $\mathrm{DM}(\mathrm{n}=112)$ & $\mathrm{IGT}(\mathrm{n}=8)$ \\
\hline NAFLD & $92(76.7 \%)$ & $89(74.2 \%)$ & $3(2.5 \%)$ \\
HBV infection & $10(8.3 \%)$ & $8(6.7 \%)$ & $2(1.7 \%)$ \\
HCV infection & $5(4.2 \%)$ & $5(4.2 \%)$ & $0(0 \%)$ \\
NAFLD and HBV infection & $4(3.3 \%)$ & $4(3.3 \%)$ & $0(0 \%)$ \\
Unidentified & $9(7.5 \%)$ & $6(5 \%)$ & $3(2.5 \%)$ \\
\hline
\end{tabular}

\section{Discussion:}

Persistent elevation of ALT in asymptomatic patient accounts much of the challenge in clinical practice. In the United States, NAFLD is replacing alcoholic hepatitis and viral hepatitis as the most common etiology of chronically elevated serum ALT in both diabetic and non-diabetic individuals and $60-95 \%$ of them are obese. ${ }^{17}$ In two different studies the prevalence of elevated ALT was considerably higher than in general population. ${ }^{18,19}$ In the current study the prevalence of elevated ALT $(>1.5$ times of UNL) in newly detected IGT and $\mathrm{DM}$ was $3.1 \%$.

NAFLD as the cause of raised ALT in our study was much higher than other studies, which may indicate insulin resistance as an important contributory factor in Bangladeshi diabetic and IGT population. ${ }^{20,21}$ It was seen that the prevalence of HBV infection was higher among persons with diabetes than without diabetes. ${ }^{8}$ In different studies HBV sero-positivity was found 2$4 \%$ but in our study it was much higher. ${ }^{22,} 23$ The frequency of anti-HCV sero-positivity was lower in our study than two other studies. ${ }^{24,25}$

In different studies, male gender, younger age, greater waist circumference, presence of type $2 \mathrm{DM}$, poor glycaemic control, BMI $>25 \mathrm{~kg} / \mathrm{m}^{2}$, long duration of DM were significant factors associated with an elevated serum ALT level. ${ }^{19,26-28}$ On the other hand, high activity of ALT independent of age and obesity is associated with the occurrence of type $2 \mathrm{DM}$ and metabolic syndrome. ${ }^{29,30}$ In our study, elevated ALT had a significant correlation with the age and metabolic syndrome.

Our study had some limitations. Study sample was small and study period was short. Fibro-scan and liver biopsy was not done and NAFLD was diagnosed by USG only. Age and sex matched large-scale prospective study may provide more detail information. Liver biopsy should be considered for histological confirmation of etiology of raised serum ALT level.

In conclusion it could be said that mild to moderate elevation of serum ALT is a common in IGT and DM. So, serum ALT level should be checked in every diabetic patient at diagnosis and at regular intervals thereafter. NAFLD is the most common etiological factor followed by HBV and HCV infection.

\section{References:}

1. Kim HC, Nam CM, Jee SH, Han KH, Oh DK, Suh II. Normal serum aminotransferase concentration and risk of mortality from liver diseases: prospective cohort study. Br Med J 2004; 328: 983-87.

2. Daniel S, Ben-Menachem T, Vasuvedan G, Blumenkchl M. Prospective evaluation of unexplained chronic liver transaminase abnormalities in asymptomatic and symptomatic patients. Am J Gastroenterol 1999; 94: 3010-14.

3. Cusi K. Nonalcholic fatty liver disease in type 2 diabetes mellitus. Curr opin Endocrin Diab Obes 2009;16(2): 141-49.

4. Naing C, Mak JW, Ahmed SI, Maung M. Relationship between hepatitis $\mathrm{C}$ virus infection and type 2 diabetes mellitus: Meta analysis. World J Gastroenterol 2012; 18 (14): 1642-51.

5. Wang CS, Wang ST, Yao WJ, Chang TT, Chou P. Hepatitis $\mathrm{C}$ virus infection and development of type $2 \mathrm{DM}$ in a community based longitudinal study. Am J Epidemiol 2008; 167(6): 751-71.

6. Zein CO, Levy C, Basu A, Zein NN. Chronic hepatitis C and type 2 diabetes mellitus: a prospective cross-sectional study. Am J Gastroenterol 2005; 100:48-55.

7. Giordanino C, Ceretto S, Bo S, Smedile A, Ciancio A, Bugianesi $\mathrm{E}$ et al. Type 2 diabetes mellitus and chronic hepatitis C: which is worse? Results of a long-term retrospective cohort study. Dig Liver Dis 2012; 44(5): 406-12. 
8. Schillie SF, Xing J, Murphy TV, Hu DJ. Prevalence of hepatitis B virus infection among persons with diagnosed diabetes mellitus in the United States, 1999-2010. J Viral Hep 2012; 19: 674-76.

9. Demir M, Serin E, Gokturk S, Ozturk NA, Kulaksizoglu S, Ylmaz U. The prevalence of ocult hepatitis B virus infection in type 2 diabetes mellitus patients. Eur J Gastroenterol Hepatol 2008; 20 (7): 668-73.

10. Vozarova B, Stefan N, Lindsay RS, Saremi A, Pratley RE, Bogardus $C$ et al. High ALT is associated with decreased hepatic insulin sensitivity and predicts the development of type 2 DM. Diabetes 2002; 51: 1889-95.

11. Clark JM. The epidemiology of nonalcoholic fatty liver disease in adults. J Clin Gastroenterol 2006; 40(3): 5-10.

12. Chitturi S, Farrell GC, Hashimoto E, Saibara T, Lau GK, Sollano JD. Non-alcoholic fatty liver disease in the AsiaPacific region: definitions and overview of proposed guidelines. J Gastroenterol Hepatol 2007;22(6):778-87.

13. El-Serag HB, Tran T, Everhart JE. Diabetes increases the risk of chronic liver disease and hepatocellular carcinoma. Gastroenterology 2004;126:460-68.

14. Davila JA, Morgan RO, Shaib Y, McGlynn KA, El-Serag HB. Diabetes increases the risk of hepatocellular carcinoma in the United States: a population based case control study. Gut 2005; 54: 533-39.

15. Hashizume H, Sato K, Takagi H, Hirokawa T, Kojima A, Sohara N. Primary liver cancers with nonalcoholic steatohepatitis. Eur J Gastroenterol Hepatol 2007;19: 827-34.

16. Amarapurkar DN, Patel ND, Kamani PM. Impact of diabetes mellitus on outcome of hepatocellular carcinoma. Ann Hepatol 2008;7:148-51.

17. Neuschwander-Tetri BA, Caldwell S. Nonalcoholic steatohepatitis: summary of AASLD single topic conference. Hepatology 2003; 37: 1202-19.

18. West J, Brousil J, Gazis A, Jackson L, Mansell P, Bennett A. Elevated serum alanine transaminase in patients with type 1 or type 2 diabetes mellitus. QJM 2006; 99(12): 871-76.

19. Meybodi MA, Afkhami M, Rashidi M. Prevalence of abnormal serum alanine aminotransferase levels in type
2 diabetic patients in Iran. Pak J Biol Sci 2008; 11: 2274-77.

20. Merat S, Yarahmadi S, Tahaghoghi S, Alizadeh Z, Sedighi N, Mansournia N. Prevalence of fatty liver disease among type 2 diabetes mellitus patients and its relation to insulin resistance. Middle East J Digest Dis 2009; 1 (2): 74-79.

21. Krishnan A, Venkataraman J. Prevalence of nonalcoholic fatty liver disease and its biochemical predictors in patients with type 2 diabetes mellitus. Exp Clin Hep 2011;7:7-10.

22. Bayramer HF, Erdem I, Gündoðdu TT, Çýnar Y, Barut Y, Demirtunç R. The prevalence of hepatitis B and hepatitis C virus in diabetic patients. Cilt 2001;14:160-64.

23. Ahmed S, Ali N, Abdullah Z, Ilyas M, Naeem U. Study of raised alanine aminotransferase in patients of type 2 diabetes mellitus. Pak Armed Forces Med J 2008;58(3):121-24.

24. Sobia SA, Irum SA, Aamir AH, Jadoon Z, Inayatullah S. Frequency hepatitis of $\mathrm{C}$ infection in diabetic patients. $\mathrm{J}$ Ayub Med Coll Abbottabad 2007; 19(1): 234-39.

25. Han Ni, Moe S, Htet A. Hepatitis C virus infection in diabetes mellitus patients. Int J Coll Res Int Med Pub Health 2012; 4(5): 599-606.

26. Liu CM, Tung TS, Liu JH, Chen VTK, Lin CH, Hsu CT et al. A community-based epidemiological study of elevated serum alanine aminotransferase levels in Kinmen, Taiwan. World J Gastroenterol 2005;11(11): 1616-22.

27. Salmela PI, Sotaniemi EA, Niemi M, Maentausta O. Liver function tests in diabetic patients. Diabetes Care 1984;7:248-54.

28. Hermos JA, Cohen SA, Hall R, Gagnon DR, Brophy MT, Fiore LD. Association of elevated alanine aminotransferase with BMI and diabetes in older veteran outpatients. Diabetes Res Clin Pract 2008; 80:153-58.

29. Schindhelm RK, Dekker JM, Nijpels G, Stehouwer CD, Bouter LM. Alanine aminotransferase and the 6-year risk of the metabolic syndrome in Caucasian men and women: the Hoorn Study. Diabet Med 2007; 24(4): 430-35.

30. Doi Y, Kubo M, Yonemoto K, Ninomiya T, Iwase M, Tanizaki Y et al. Liver enzymes as a predictor for incident diabetes in a Japanese population: the Hisayama study. Obesity 2007; 15(7): 1841-50. 